\title{
Association of Insulin Receptor Substrate-1 G972R Variant with Non-small Cell Lung Cancer Risk
}

${ }^{1}$ Department of Internal Medicine, ${ }^{2}$ The Institute of Chest Diseases, ${ }^{3}$ Brain Korea 21 Project for Medical Sciences, ${ }^{4}$ Cancer Metastasis Research Center, Yonsei University College of Medicine, Seoul, Korea

Chang Youl Lee, M.D. ${ }^{1}$, Chul Min Ahn, M.D., ${ }^{1,2}$, Jeong Hee Jeon, M.D. ${ }^{3}$, Hyung Jung Kim, M.D. ${ }^{1,2}$, Se Kyu Kim, M.D. ${ }^{1,2,3,4}$, Joon Chang, M.D. ${ }^{1,2}$, Sung Kyu Kim, M.D. ${ }^{1,2}$, Yoon Soo Chang, M.D.,

Background: The insulin receptor substrate-1 (IRS-1) is the primary docking molecule for the insulin-like growth factor I receptor (IGF-IR), and is required for activation of the phosphatidylinositol 3'-kinase (PI3K) pathway. IRS-1 activation of the (PI3K) pathway regulates IGF-mediated survival, enhancement of cellular motility and apoptosis. Therefore, we attempted to ascertain whether IRS-1 genetic variations affect an individual's risk for non-small cell lung cancer (NSCLC).

Methods: Two-hundred and eighteen subjects, either diagnosed with NSCLC or control subjects, were matched by age, gender and smoking status. Genomic DNA from each subject was amplified by PCR and analyzed according to the restriction fragment length polymorphism (RFLP) profile to detect the IRS-1 G972R polymorphism.

Results: The frequencies of each polymorphic variation, in the control population, were as follows: GG=103 (94.5\%) and GR=6 (5.5\%); for the NSCLC subjects, the genotypic frequencies were as follows: GG=106 (97.2\%) and GR=3 $(2.8 \%)$. We could not demonstrate statistically significant differences in the genotypic distribution between the NSCLC and the control subjects ( $\mathrm{p}=0.499$, Fisher's Exact test). The relative risk of NSCLC, associated with the IRS-1 G972R polymorphic variation, was 1.028 (95\% CI; 0.63 9.90). In addition, we found no differences between polymorphic variants with regard to the histological subtype of NSCLC.

Conclusion: We did not observe any noteworthy differences in the frequency of the IRS-1 G972R polymorphism in NSCLC patients, compared to control subjects. These results suggest suggesting that, in our study population, the IRS-1 G972R polymorphism does may not appear to be associated with an increased risk of NSCLC.

Key Words: Insulin receptor substrate-1, Insulin-like growth factor, Non-small cell lung cancer

\section{Introduction}

Non-small cell lung cancer (NSCLC) accounts for approximately $75 \sim 80 \%$ of all lung cancers and is the leading cause of cancer-related death worldwide.

This work was supported by the Korea Science and Engineering Fund through the Cancer Metastasis Research Center at Yonsei University, Seoul, Korea.

Address for correspondence: Yoon Soo Chang, M.D. Deparatment of Internal Medicine, 8th Floor Annex Building, Gangnam Severance Hospital, 712, Eonju-ro, Dogokdong, Gangnam-gu, Seoul 135-720, Korea

Phone: 82-2-2019-3309, Fax: 82-2-3463-3882

E-mail: yschang@yuhs.ac

Received: Jun. 13, 2006

Accepted: Sep. 7, 2006

This work was published in the Journal of Lung Diseases Volume 1, Number 1, Page 22 27.
NSCLC is presumed to be caused by complex interactions between genetic and environmental factors. Epidemiologic studies suggest that, in addition to environmental factors, common genetic variations that have low penetration but high attributable risk may play an important role in the development of NSCLC.

Insulin-like growth factors (IGFs) are synthesized by almost all tissues and regulate cell proliferation, differentiation, and apoptosis; all important cell processes that contribute to tumorigenesis ${ }^{1}$. Several studies on cancer risk factors have suggested that high levels of circulating IGF-1 are associated with an increased risk of solid cancers, including NSCLC ${ }^{2-5}$. The binding of IGF-1 to its receptor (IGF-IR) results in receptor autophosphorylation and the subsequent phosphorylation of 
Shc and insulin receptor substrates (IRS)-1, -2, -3, and $-4^{6}$. Although IGF signaling is transduced intracellularly, via an extensive signaling network with multiple alternative pathways, IRS- 1 is the first basic cytosolic mediator $^{7-10}$. IRS-1 is the primary docking molecule for IGF-IR and is required for activation of the phosphatidylinositol 3'-kinase (PI3K) pathway, which regulates IGF-mediated survival and enhancement of cellular motility, and is anti-apoptotic. IRS-1 is also required for activation of the RAS-mitogen-activated protein kinase pathway, which regulates cell proliferation.

Phosphorylation of IRS-1 at Tyr ${ }^{608}$ and $\mathrm{Tyr}^{628}$ (using numbering based on the rat IRS-1 amino acid sequence) generates the major docking sites for PI3K and activates multiple signaling pathways including: PI3K, mitogenactivated protein kinase (MAPK) and $\mathrm{Akt}^{11,12}$. On the other hand, IRS-1 serine/threonine phosphorylation of 50 potential sites is thought to oppose the biologic activity that is induced by tyrosine phosphorylation ${ }^{13}$. In addition to IRS-1 phosphorylation, chronic exposure to IGFs, mannitol, okadaic acids, high glucose and hyperinsulinemia decrease cellular IRS-1 levels, which, in turn, diminish a cell's response to apoptotic signals ${ }^{11,12}$. By extension, a delicate balance between "positive" IRS-1 tyrosine phosphorylation and "negative" serine/ threonine phosphorylation, with decreased IRS-1 levels may regulate the function of IRS-1. Shifts in this equilibrium could lead to pathological situations ${ }^{13}$.

In addition to posttranslational modifications, the most commonly detected polymorphism in human IRS1, a glycine to arginine change at codon 972 (G972R), is associated with an increased risk of insulin resistance and a variety of cancers ${ }^{14,15}$. The G972R polymorphism is found near the C-terminus of IRS-1 and is flanked by two tyrosine phosphorylation consensus sites $\left(\mathrm{EY}^{941}\right.$ MLM and DY ${ }^{989}$ MTM), known binding sites for the p85 $\alpha$ regulatory subunit of PI3-kinase. The G972R IRS-1 polymorphism not only reduces substrate phosphorylation, but also allows IRS-1 to act as an inhibitor of the insulin receptor kinase, producing a global insulin resistance that is associated with several types of can$\operatorname{cer}^{14,16}$.
Thus, we hypothesized that the IRS-1 G972R polymorphic variation may affect an individual's risk for NSCLC. We investigated this potential relationship, using PCR-RLFP analysis to identify the G972R polymorphism in our study population.

\section{Materials and Methods}

\section{Study population and samples}

We used genomic DNA, isolated from 109 patients, who had been diagnosed with NSCLC and had undergone surgery between 1995 and 1998, for the management of primary tumors at Yonsei Medical Center, Seoul, South Korea. The NSCLC cases included 86 male and 23 female patients, and the mean age was $58.4 \pm$ 10.52 years. The control subjects were matched according to age gender and smoking status with the NSCLC patients. Blood samples were selected from a blood bank, comprising 1,038 subjects who had visited Yong-In Severance Hospital at Yonsei University Medical College in 2003, for an annual health examination, conducted by the National Health Insurance Institute of Korea. The matched control subjects included 86 males and 23 females with a mean age of $55.8 \pm 10.79$ years (Table 1). The use of these samples and our experimental protocol were reviewed and approved by our institutional review board.

\section{PCR and restriction fragment length polymorphism (RFLP) analysis}

The genomic DNAs were extracted from blood samples, using a QIAamp Blood Kit (Qiagen, Hilden, Ger-

Table 1. Description of the study population

\begin{tabular}{llccc}
\hline & & $\begin{array}{c}\text { NSCLC } \\
\mathrm{n}(\%)\end{array}$ & $\begin{array}{c}\text { Control } \\
\mathrm{n}(\%)\end{array}$ & p-value \\
\hline Age, yr & Mean \pm S.D. & $58.4 \pm 10.52$ & $55.8 \pm 10.79$ & 0.077 \\
Gender & Male & 86 & 86 & \\
& Female & 23 & 23 & \\
Smoking & Current & 75 & 62 & 0.181 \\
history & Ex-smoker & 14 & 21 & \\
& Non-smoker & 20 & 26 & \\
\hline
\end{tabular}



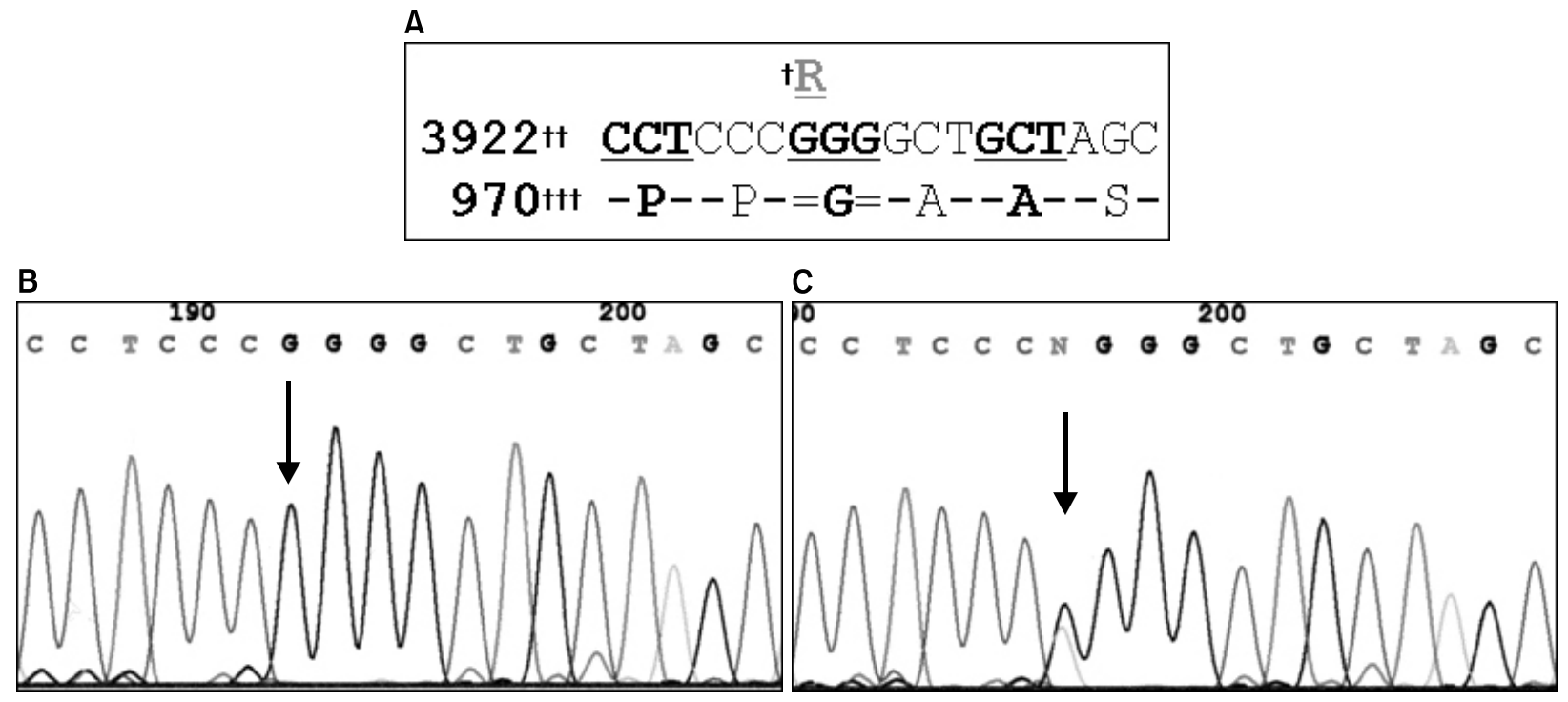

Figure 1. Sequence of exon, translation (A) and polymorphic variants $(B, C)$ of IRS-1. Note homozygotic $(G / G)(B)$ and heterozygotic $(G / A)(C)$ variant of IRS-1. ${ }^{+}$IUB code name (R means nucleotide $A$ and $\left.G\right)$. Numbering of the exon ${ }^{++}$ and amino acid residue ${ }^{++\dagger}$ was adapted from Gene Bank Acc. \#NM_005544.

many), or by the standard method, using proteinase-K digestion, followed by phenol/chloroform extraction. The 243-base-pair (bp) fragment, encompassing the G972R polymorphic site in the IRS-1 gene, was amplified using the following specific primers: 5'-TTTGGG AGTGATCAG TCTGGCTAC-3' for the sense strand and 5'-CGGGTAGGCCTGCAAATGCTA-3' for the antisense strand. The PCR reactions were performed in a $25-\mu \mathrm{L}$ volume, containing $20 \mathrm{ng}$ of genomic DNA, 2.5- $\mu \mathrm{L} 10$ X PCR buffer, $0.2 \mathrm{mM}$ of each deoxyribonucleotide triphosphate (dATP, dCTP, dGTP and dTTP), $1 \mathrm{mM}$ $\mathrm{MgCl}_{2}, 50 \mathrm{pM}$ of each primer, and 1 unit of Ampli-Taq Gold DNA polymerase (Perkin-Elmer, Branchburg, NJ, USA). After an initial 10-min denaturation step at $95^{\circ} \mathrm{C}$, 40 cycles of PCR reactions, consisting of incubations at $95^{\circ} \mathrm{C}$ for $30 \mathrm{sec}, 60^{\circ} \mathrm{C}$ for $1 \mathrm{~min}$, and $72^{\circ} \mathrm{C}$ for $1 \mathrm{~min}$ were completed. These were followed by a final 15 -min extension step at $72^{\circ} \mathrm{C}$. All PCR reactions were performed in a thermal cycler (GeneAmp PCR System 9700; Perkin-Elmer). After confirming the successful PCR amplification by visualization, using $2.5 \%$ agarose gel electrophoresis, each PCR product was digested for $2 \mathrm{hr}$ with 5 units of SmaI enzyme (New England Biolabs, Beverly, MA, USA) at $25^{\circ} \mathrm{C}$ and then electrophoresed on

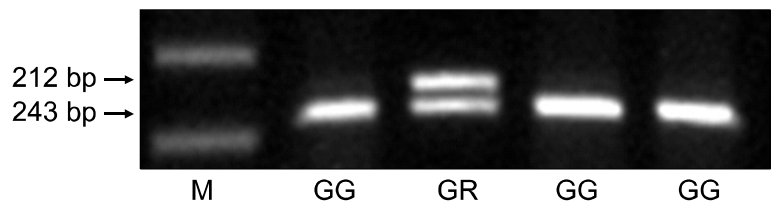

Figure 2. IRS-1 G972R polymorphic variants. The representative data from PCR-RFLP are presented in this figure. Heterozygote $(G / A)$ is shown in lane 3 and homozygote $(G / G)$ in lanes 2, 4 and 5. M: DNA size marker (lane 1).

a 2.5\% agarose gel. When the SmaI restriction site was present, the 243-bp PCR fragment was divided into 212and 31-bp fragments. The allele was designated either G or A, depending on whether the SmaI restriction site was present or absent, respectively. The validity of the PCR-RFLP analysis was verified by direct sequencing of several PCR samples of each genotype from Genotech Co. Ltd. (Daejun, Korea), using the previously described sense and antisense primers (Figure 1,2).

\section{Statistical analysis}

A Fisher's exact test was employed for comparison of the genotypic frequencies between the NSCLC and the control groups (Table 2). The odds ratio (OR) and 
Tuberculosis and Respiratory Diseases Vol. 67. No. 1, Jul. 2009

Table 2. Frequency of IRS1 genotype and ORs and $95 \%$ Cls for their association with prostate cancer in sibling-based study

\begin{tabular}{crrc}
\hline $\begin{array}{c}\text { Gene varinat } \\
\text { (IRS-1 G972R) }\end{array}$ & $\begin{array}{c}\text { NSCLC } \\
\mathrm{n}(\%)\end{array}$ & $\begin{array}{c}\text { Control } \\
\mathrm{n}(\%)\end{array}$ & $\begin{array}{c}\text { OR } \\
(95 \% \text { Cl) }\end{array}$ \\
\hline GG & 106 & 103 & 1.0 (reference) \\
GR & 3 & 6 & $1.028(0.63 \sim 9.90)^{+}$ \\
\hline
\end{tabular}

*adjused for age, ${ }^{\dagger} \mathrm{OR}$ and $95 \% \mathrm{Cl}$ for $\mathrm{Arg} / \mathrm{Arg}$ and Gly/Arg comgined.

95\% confidence interval (CI) with regard to the IRS-1 genotypes were calculated, using conditional logistic regression analysis.

\section{Results}

\section{Control subject group characteristics and IRS-1 G972R genotypes}

The age, gender and smoking status-matched control subjects included 86 males and 23 females with a mean age of $55.8 \pm 10.79$ years (Table 1). The frequencies of each polymorphic variation at amino acid 972 of IRS-1 in the control population were as follows: $G G=103$ (94.5\%) and $\mathrm{GR}=6$ (5.5\%) (Table 2). Personal medical histories including: diabetes, hypertension and cerebrovascular accidents, were not affected by the IRS-1 G972R genotype in the control subjects (data not shown).

\section{NSCLC patient characteristics and IRS-1 GR972R genotypes}

The NSCLC cases included 86 male and 23 female patients with a mean age of $58.4 \pm 10.52$ years, comparable to the age distribution of the control population. The NSCLC population frequencies of each polymorphic variation at amino acid 972 in the IRS-1 gene were as follows: GG=106 (97.2\%) and GR=3 (2.8\%; Table 2). We found no apparent differences in the allelic frequencies when the NSCLC patients were compared with the gender-, age- and smoking status-matched control subjects (Fisher's exact test).
Table 3. Frequency of IRS-1 genotype with regard to pathologic stage and subtype of NSCLC

\begin{tabular}{llrcr}
\hline & & Genotype & p-value* \\
\hline \multirow{4}{*}{ pStage } & I & GG & GR & \\
& II & 39 & 0 & 0.571 \\
& III & 20 & 1 & \\
& IV & 43 & 2 & \\
Pathologic & Adenocarcinoma & 5 & 0 & \\
subtype & Squamous cell carcinoma & 48 & 2 & 0.738 \\
& Other cell types & 6 & 0 & \\
\hline
\end{tabular}

*Fisher's Exact test

\section{IRS-1 G972R polymorphism and the risk of NSCLC}

In order to examine whether the risk of NSCLC is related to the IRS-1 genotype, we conducted a conditional logistic regression analysis. Compared to the subjects with a GG genotype, the subjects with a GR genotype did not have a higher risk for NSCLC. The relative risk of NSCLC associated with the G972R polymorphism was 1.028 (95\% CI; 0.63 9.90). Our study included 39 (35.8\%) patients with pathologic stage (pstage) I (IA and IB), 21 patients (19.3\%) with pstage II (IIA and IIB), 45 patients (41.3\%) with pstage III (IIIA and IIIB) and 4 patients (3.7\%) with pstage IV. The IRS-1 G972R polymorphism had no appreciable influence on the tumor pstage at the time of initial diagnosis (Table 3). The NSCLC cases in our study included the following histological cancer subtypes: 53 (48.6\%) adenocarcinomas, $50(45.9 \%)$ squamous cell carcinomas, and $6(5.5 \%)$ cases with other cell types, including undifferentiated, as well as large cell carcinoma. The distribution of each genotype did not differ with regard to the histological NSCLC subclassification (Table 3).

\section{Discussion}

There were few differences in the genotypic distribution between the study populations, where $4.1 \%$ had the GR allele; these results conformed to Hardy- 
Weinberg equilibrium. Other studies that evaluated the IRS-1 G972R polymorphism have reported a 5\% rate of this genetic polymorphism. In our study, $5.5 \%$ of the control subjects had the IRS-1 G972R genetic polymorphism, which is in agreement with previous studies.

IRS-1 is the major cytoplasmic substrate of the insulin receptor in most insulin-sensitive tissues. Some studies suggest that IRS-1 plays an important role in regulating insulin secretion in the pancreatic $\beta$ cells ${ }^{20,21}$. Of the many IRS-1 gene polymorphisms that have been described, the glycine-to-arginine substitution at codon 972 (G972R) has been studied in conjunction with obesity, polycystic ovary syndrome and non-insulin-dependent diabetes, thus making this polymorphism a plausible variant that may alter cancer risk. The $\mathrm{R}$ allele has been associated with impaired insulin-associated signaling and insulin resistance is hypothesized to be associated with various cancers; therefore a slight increase in the risk associated with the $\mathrm{R}$ allele could actually be an indirect result of the association of the $\mathrm{R}$ allele with obesity, decreased insulin sensitivity, diabetes, as well as altered insulin action and secretion.

It has been suggested in the literature that insulin and IGFs may contribute substantially to the risk of many types of cancer. Polymorphisms in the genes that are involved in the regulation of IGFs serum levels may be associated with NSCLC. While many genes are involved in the process of regulating insulin-related factors, we assessed an IRS-1 polymorphism that had previously been shown to have functional significance in the regulation of hormone levels and may, therefore, influence NSCLC risk.

We observed no noteworthy difference between the frequencies of the IRS-1 G972R polymorphism in the case and the control populations. Conditional logistic regression analyses revealed no association between the polymorphism and NSCLC risk. The distribution of each polymorphic genotype did not differ with regard to the histological NSCLC subclassification. Some studies have reported that IRS-1 G972R genotypes resulted in a 70\% increased risk of colon cancer ${ }^{15}$. However, the IRS-1 G972R genotype has not been shown to be associated with an increased risk of NSCLC.

In conclusion, we did not detect any noteworthy difference in the frequencies of the IRS-1 G972R polymorphism when comparing cases to controls, suggesting that the IRS-1 G972R polymorphism may not be a marker for significant risk for NSCLC in our population.

\section{References}

1. Le Roith D. Seminars in medicine of the Beth Israel Deaconess Medical Center: insulin-like growth factors. N Engl J Med 1997;336:633-40.

2. Yu H, Spitz MR, Mistry J, Gu J, Hong WK, Wu X. Plasma levels of insulin-like growth factor-I and lung cancer risk: a case-control analysis. J Natl Cancer Inst 1999;91:151-6.

3. Chan JM, Stampfer MJ, Giovannucci E, Gann PH, Ma J, Wilkinson P, et al. Plasma insulin-like growth factor-I and prostate cancer risk: a prospective study. Science 1998;279:563-6.

4. Hankinson SE, Willett WC, Colditz GA, Hunter DJ, Michaud DS, Deroo B, et al. Circulating concentrations of insulin-like growth factor-I and risk of breast cancer. Lancet 1998;351:1393-6.

5. Ma J, Pollak MN, Giovannucci E, Chan JM, Tao Y, Hennekens $\mathrm{CH}$, et al. Prospective study of colorectal cancer risk in men and plasma levels of insulin-like growth factor (IGF)-I and IGF-binding protein-3. J Natl Cancer Inst 1999;91:620-5.

6. Tsuruzoe K, Emkey R, Kriauciunas KM, Ueki K, Kahn CR. Insulin receptor substrate 3 (IRS-3) and IRS-4 impair IRS-1- and IRS-2-mediated signaling. Mol Cell Biol 2001;21:26-38.

7. Cheatham B, Kahn CR. Insulin action and the insulin signaling network. Endocr Rev 1995;16:117-42.

8. Smith RM, Harada S, Jarett L. Insulin internalization and other signaling pathways in the pleiotropic effects of insulin. Int Rev Cytol 1997;173:243-80.

9. White MF, Maron R, Kahn CR. Insulin rapidly stimulates tyrosine phosphorylation of a Mr-185,000 protein in intact cells. Nature 1985;318:183-6.

10. White MF, Kahn CR. The insulin signaling system. J Biol Chem 1994;269:1-4.

11. Esposito DL, Li Y, Cama A, Quon MJ. Tyr (612) and Tyr (632) in human insulin receptor substrate-1 are important for full activation of insulin-stimulated phosphatidylinositol 3-kinase activity and translocation of GLUT4 in adipose cells. Endocrinology 2001;142:2833-40. 
12. Kim B, van Golen CM, Feldman EL. Insulin-like growth factor I induces preferential degradation of insulin receptor substrate-2 through the phosphatidylinositol 3kinase pathway in human neuroblastoma cells. Endocrinology 2005;146:5350-7.

13. Delafontaine P, Song YH, Li Y. Expression, regulation, and function of IGF-1, IGF-1R, and IGF-1 binding proteins in blood vessels. Arterioscler Thromb Vasc Biol 2004;24:435-44.

14. McGettrick AJ, Feener EP, Kahn CR. Human insulin receptor substrate-1 (IRS-1) polymorphism G972R causes IRS-1 to associate with the insulin receptor and inhibit receptor autophosphorylation. J Biol Chem 2005;280: 6441-6.

15. Slattery ML, Samowitz W, Curtin K, Ma KN, Hoffman M, Caan B, et al. Associations among IRS1, IRS2, IGF1, and IGFBP3 genetic polymorphisms and colorectal cancer. Cancer Epidemiol Biomarkers Prev 2004;13: 1206-14

16. Hsing AW, Gao YT, Chua S Jr, Deng J, Stanczyk FZ. Insulin resistance and prostate cancer risk. J Natl Cancer Inst 2003;95:67-71.
17. Stumvoll M, Fritsche A, Volk A, Stefan N, Madaus A, Maerker E, et al. The Gly972Arg polymorphism in the insulin receptor substrate-1 gene contributes to the variation in insulin secretion in normal glucose-tolerant humans. Diabetes 2001;50:882-5.

18. Sesti G, Federici M, Hribal ML, Lauro D, Sbraccia P, Lauro R. Defects of the insulin receptor substrate- 1 (IRS) system in human metabolic disorders. FASEB J 2001;15:2099-111.

19. Almind K, Inoue G, Pedersen O, Kahn CR. A common amino acid polymorphism in insulin receptor substrate-1 causes impaired insulin signaling. J Clin Invest 1996;97:2569-75.

20. Rosen CJ, Glowacki J, Craig W. Sex steroids, the insulin-like growth factor regulatory system, and aging: implications for the management of older postmenopausal women. J Nutr Health Aging 1998;2:39-44.

21. Kido Y, Nakae J, Hribal ML, Xuan S, Efstratiadis A, Accili D. Effects of mutations in the insulin-like growth factor signaling system on embryonic pancreas development and $\beta$-cell compensation to insulin resistance. J Biol Chem 2002;277:36740-7. 